\title{
Willingness to sell wheat to the government: a case study in Golestan province of Iran
}

\author{
Mojtaba Mojaverian \\ Department of Agricultural Economics, Sari Agricultural Sciences and Natural Resources University, Iran \\ mmojaverian@yahoo.com
}

\begin{abstract}
In Iran, especially after the revolution, there has been extensive support for the self-sufficiency in wheat production, including government procurement. If this trend continues, the market mechanism will be inactive. In this study the factors influencing the increasing tendency of producers to sell the products have been studied in Golestan province. For this purpose, the wheat supply function in an Autoregressive Distributed Lag (ARDL) model was estimated utilizing collected data from 252 wheat producers in this area. In this model, the sale to production ratio was used instead of sale quantity which normally used in literature, because the production quantity is a dominant variable and could eliminate the effect of other variables. The results showed that growth in production does not have any important effect on this tendency. On the other hand, relative prices, selling customs and self-consumption rate, have meaningful effect on this willingness to sell tendency. Also there has been no significant difference between large and small producers. Based on these results, the producers' behavior can be interpreted by price signals even in the semi-traditional agriculture. Also by transition from self-sufficiency based economy to a market based economy, this variable becomes more effective.
\end{abstract}

Keywords: Wheat, guarantee purchase, Golestan province, willingness to sell.

\section{Introduction}

Wheat is one of the important and strategic productions in agricultural products, not only in Iran but also in the worldwide. The data from recent years show that per capita consumption of wheat in the world is about $70 \mathrm{~kg}$, in Iran it was estimated about $130 \mathrm{~kg}$ for urban areas and $185.6 \mathrm{~kg}$ for rural areas. The ratio of international trade to production for wheat is about $20 \%$. The amount of subsidy paid from state for wheat in recent years was about $80 \%$ of whole subsidy of all goods.

Because of the importance of wheat, government does some support in input and output market. In Iran the supporting policies are as compensatory payments, the wheat is bought at the guarantee price from the producers and given at the stabilization price to the processing units.

Table 1. Golestan province status from the view point of acreage, output and yield in the Iran.

\begin{tabular}{|c|c|c|c|c|c|c|}
\hline \multirow{2}{*}{ year } & \multicolumn{2}{|c|}{ Production area } & \multicolumn{2}{|c|}{ Output } & \multicolumn{2}{|c|}{ Yield } \\
\cline { 2 - 7 } & ranking & $\begin{array}{c}\text { Percent of } \\
\text { whole } \\
\text { country }\end{array}$ & ranking & $\begin{array}{r}\text { Percent of } \\
\text { whole country }\end{array}$ & $\begin{array}{c}\text { Irrigated } \\
\text { ranking }\end{array}$ & $\begin{array}{c}\text { Dry } \\
\text { ranking }\end{array}$ \\
\hline 1996 & 13 & 2.8 & 8 & 4.2 & 8 & 1 \\
\hline 2000 & 7 & 6 & 4 & 8 & 11 & 2 \\
\hline 2004 & 8 & 5.9 & 4 & 7.6 & 21 & 1 \\
\hline 2009 & 10 & 5.7 & 4 & 8.2 & 16 & 3 \\
\hline
\end{tabular}

Table 2. Comparing the status of wheat purchase in Golestan province and country

\begin{tabular}{|l|c|c|c|c|}
\hline Year & $\begin{array}{c}\text { Province } \\
\text { purchase } \\
(1000 \text { tons) }\end{array}$ & $\begin{array}{c}\text { Country purchase } \\
\text { (thousand tons) }\end{array}$ & $\begin{array}{c}\text { Raito of purchase to } \\
\text { production (percent) }\end{array}$ & $\begin{array}{c}\text { Raito of province } \\
\text { purchase to } \\
\text { country (percent) }\end{array}$ \\
\hline 1981 & 88 & 901 & 25,58 & 9,75 \\
\hline 1991 & 454 & 2439 & 71,98 & 18,60 \\
\hline 2001 & 736 & 8654 & 92,64 & 8,51 \\
\hline 2010 & 958 & 10931 & 87 & 8.8 \\
\hline Aver & 403 & 3359 & 64,55 & 15,33 \\
\hline
\end{tabular}

Popular article

COIndian Society for Education and Environment (iSee)

"Willingness to sell wheat for public distribution in Iran" http://www.indjst.org The tendency of producers from this kind of selling
(selling to the state) will make the government supporting policies succeed. Statistics of selling wheat to state in recent years has shown a growth in the ratio of selling to the state from the whole production. This ratio in 2002 was $75 \%$ of the production. Finding the effective reasons on the growth of selling wheat to state and showing the amount of effect on the policy makers are needed.

The main question in this study looks for reasons of increase in selling wheat to state by the producers. The hypotheses that are examined to answer this question are: a) Increase in guarantee price has led the producers to sell to state. b) Relative decrease at livestock's food price will motivate the selling to state. c) The wheat producers are traditionalism in selling their productions and choose this way by habit. d) The increase in amount of buying centers has led the producers to sell to state. e) Decrease in self consumption has made the increase of selling tendency to state

Wheat was always the main production in Golestan province. Acreage and amount of output in year 2009 was 379 thousand hectares and 1101 thousand tons. The annual average increase in wheat acreage in this province was 0.9 percent that is more than the increase in the country in the same period (Table 1).

Source: Statistics and information technology office, Agricultural statistic book (first volume) Cultivation and horticultural productions (different cultivation years), Programming and economical assistant of agricultural ministry.

Mojtaba Mojaverian Indian J.Sci.Technol. 
The average yield of irrigated and dry wheat in the province is 2.9 and 2.1 ton respectively. In Golestan, the main competitive productions for wheat are Barely and Cotton. Table (1) shows the status of Golestan province in the country from the view of production area, output and yield of irrigated and dry wheat for 5 years. Table 2 presents the status of wheat purchase with guarantee price by the government in two past decades in Golestan province.

Source: Statistics office and computerizing service of agricultural planning management, rural cooperatives organization and researchers calculation. Table 2 shows that wheat purchases of province had an $8.63 \%$ growth in the study period where there is a $1.17 \%$ growth in countries wheat purchase. Also in the province, an annual average of $15.33 \%$ of countries total purchase has been taken place.

The head department of Iran's cereal has the duty to have observation on wheat purchase that it is done by Rural Cooperative Organization (RCO). From 1998 Cereal Organization (CO) has this permission of purchasing too. Although this permission is to motivate the competition between the wheat producers, but the Policy makers of the organization don't believe this competition is fine because an observant never can be a performer itself. They believe that the CO doesn't except the amount of decrease calculated by the RCO but purchase the wheat by less decrease himself.

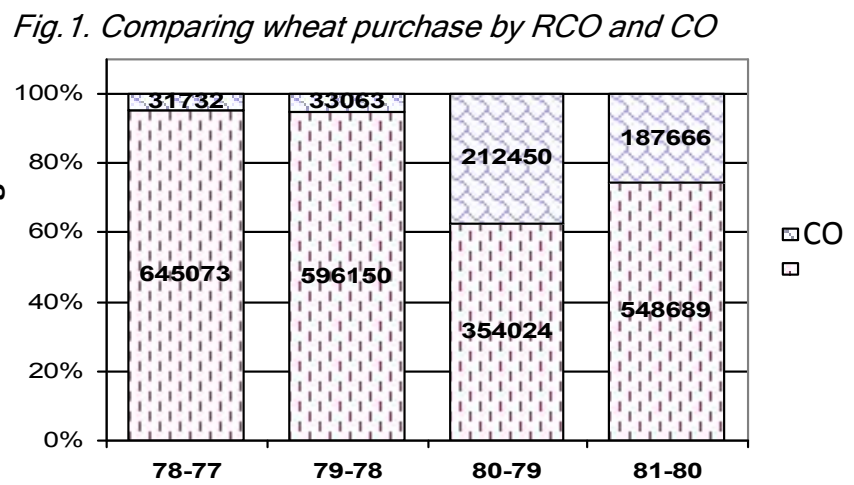

Fig. 1 shows the increase of $\mathrm{CO}$ purchase quota from the total purchase. Governments purchase policies especially for wheat has turned up to a subject that has attracted lots of researchers' attention. Morzuch et al. (1980) have studied the wheat acreage supply response under changing farm programs of the government. In this study the variations of price elasticity of product acreage supply for each wheat producer state in America has been calculated. The total estimated elasticity for spring and autumn wheat and the total has been $0.77,0.45$ and 0.52 . The sensitivity of acreage supply to price variation done by the government, between different places has a lot of heterogeneity. Some factors like size of the farms, different regions share in country's wheat market and the role of price in allocation of land between wheat and other crop products in years 1950, 1954-1964 was studied.
Vol. 5 No. 3 (Mar 2012)

ISSN: 0974- 6846

The effect of price policy on Indian wheat producers response studied by Sidhu and Baanante (1981). Application of the translog profit function to farm-level data from Punjab, India, allowed a more disaggregated analysis of the farm production structure compared to the case of Cobb-Douglas formulation. The flexibility afforded by translog formulation permitted measurement of the different impacts that exogenous variables have within and across input demand and output supply functions.

Governments typically wield their purchases as a policy tool, favoring domestic over foreign suppliers. By doing so, they aim to return tax money to domestic residents, create more jobs at home and reduce imports. The buy-American act of 1993 specifies a maximum premium over the price of imports. These premium range from 6 percent to 50 percent of import prices..However some economists have questioned this conventional wisdom. For example, Baldwin (1970, 1984), and Baldwin and David Richardson (1984) argue that, within a competitive framework, extending preferential treatment to the domestic industry neither reduces imports nor increases domestic price, output and employment. The inefficacy of discriminatory procurement follows from the fact that shifting government demand strictly toward domestic producers generates an equal and opposite shift in consumer demand toward imports. However Baldwin (1984) warns against generalizing this result to noncompetitive situation without future examination. Miyagiwa (1991) examine whether the BaldwinRichardson ineffectiveness proposition carries over to noncompetitive situation. He shows that if the goods are perfect substitute, then the Baldwin-Richardson ineffectiveness proposition continues to hold under various types of industrial organization.

Garcia and Randall (1994) estimated cost functions by crop (U.S. and French wheat and corn, and English wheat) and derived marginal costs. Fertilizer input demand and output supply elasticities, estimated via marginal cost, are computed capturing the effect of fertilizer-reducing policies (a tax and a quota). Supply and fertilizer demand effects are compared within and across countries. The results generally support the hypothesis that fertilizer-reducing policies have a greater effect on crop supplies that use fertilizer more intensively, and that fertilizer policy multilaterally imposed will give U.S. producers a relative competitive advantage vis-a-vis French and English producers.

Kherallah et al. (2003) surveyed on 800 Egyptian wheat farmers and study production, marketing channel, government purchase, supply price elasticity and input demand for wheat producers after 1987 reform. Results show that most of the wheat produced is consumed in the rural areas. The estimated own-price supply elasticity is 0.3 , implying that the use of price policy alone to pursue wheat self-sufficiency would be costly and ill-advised. Taylor (2003) developed an empirical model to examine offset arrangements in government procurement. Offsets 
are non-standard contracts that governments use to extract rents from multinational corporations. Previous contributions focus on the transaction cost. These studies are devoid of quantitative models needed to test the theoretical claims. Taylor study fills part of the gap in the literature. The results suggest that while economic variables (transaction costs, price and quality) are part of the offset selection process, political economy variables (security alliances and rent-seeking) tend to exert more influence on policy.

Evenett and Hoekman (2005) examine the effects on national welfare and market access of two public procurementpractices, discrimination and nontransparency. Both policies have become prominent in international trade negotiations, including the Doha Round of World Trade Organization (WTO) trade talks. They show that fostering either domestic competition or transparency in state contracting tends to improve welfare. In contrast, they find no clear-cut effect on market access of ending discrimination or improving transparency.

\section{Materials and methods}

\section{Methods}

The model used is a supply function (sell to government). In supply function, independence variable affect on sell to government tendency.

$\mathrm{Si} / \mathrm{Qi}=\gamma 0+\gamma 1 \mathrm{Qi}+\gamma 2(\mathrm{Qi}-\mathrm{Q}(-1) \mathrm{i}) /(\mathrm{Ai}-\mathrm{A}(-1) \mathrm{i})+\gamma 3$

(Pwi- Pw(-1)i)/( Aci-Ac(-1)i) +

$\gamma 4 \mathrm{Dsi}+\gamma 5 \mathrm{Ni}+\gamma 6$ Pbarleyi $+\gamma 7$ Managi

$+\gamma 8(\mathrm{~S}(-1) \mathrm{i} / \mathrm{Q}(-1) \mathrm{i}+\gamma 9 \mathrm{Ci}+\eta \quad$ (1)

Function (1) is the wheat supply (selling) to state by local producers. The first point in this function is choosing the dependant variable (the left side). Because of the close relationship between quantity of selling $S$ and quantity of production $\mathbf{Q}$ in estimating, when a guarantee independent variable enters the function, other variable's coefficients (that have to be examined in this study) will lose their significance. $Q$ wheat production quantity, governments guarantee price for wheat $P_{w}$, quantity of self-consumption of wheat $C$, cattle's food price as a proxy for selling wheat to state $P$ barley, have been found as the most important factors in determining quantity of selling to state.

In function (1) for simplicity, we assumed a linear relationship. The variables at the time of farmers supply are clear and real quantities (not exceptional) have been entered. One of the effective variables on the tendency of selling to state is production quantity. By choosing (Si/Qi) as the dependant variable, production quantity is no more a guarantee variable.

Ds is the distance between farm and state's wheat purchasing centers (CO's delivering centers and RCO's purchasing centers) that is determined by the survey for each farmer. However apparently it is expected to have a negative sign, which means the farmers who are closer to the wheat purchasing centers have a higher tendency to sell to state and inverse, but since the cost of wheat's transporting from the farm to purchasing centers are paid by purchasing offices we can't have any significance expectation from $\gamma_{4}$ sign.

$\mathrm{N}$ shows wheat's acreage supporting by the target purchasing centers. The target purchasing centers are the centers which the sample farmer sells his products to there. In other words, for each farmer quantity of $\mathrm{N}$ is equal to the purchasing center's environs acreage which he has sold his products there. If we assume the wheat acreage stabilized -or approximately stabilized- in different regions of Golestan province and in the period of time, by increasing in the number of purchasing centers, $\mathrm{N}$ will decrease and the farmers will deliver their wheat with more comfort. Therefore if an increase in the number of purchasing centers led to a higher tendency farmer's wheat delivery, the sign of Nin function needs to be negative.

According to the study's hypothesizes, it is needed to measure farm management's effect on selling to state and examine it. In this study level of farm management for each farmer was measured by summation of deviation from optimum consumption of inputs in production. For this, after estimating the yield function, the optimum quantity of production inputs -maximize of yield- was calculated. Then the sum of deviations from optimum was measured as below (2) and was taken as each farmer's level of farm management.

$$
\operatorname{Manag}_{\mathrm{i}}=\left|\mathrm{B}_{\mathrm{i}}-\mathrm{B}^{*}\right|+\left|\mathrm{F}_{\mathrm{i}}-\mathrm{F}^{*}\right|+\cdots
$$

Where, $\mathrm{Bi}$ and $\mathrm{Fi}$ are amounts of seed and fertilizer that used by farmer $\mathrm{i}$ respectively. $\mathrm{B}^{*}$ and $\mathrm{F}^{*}$ is optimum amount of seed and fertilizer respectively.

The range of Managi is between zero to extreme (infinite quantity). The wheat producer that produces in complete optimum manner, its Managi quantity will be zero and the more the producer produces inefficiently the quantity of this variable will increase. Using absolute value in this summation is to prevent the adjustment between positive and negative terms and implicitly means that inefficiency doesn't depend on more or less than optimum level of consumption.

Barley's price in production region is taken as cattle's price food index. Since selling to stockmen or consuming wheat at livestock units are mentioned as two competitive markets for selling to state, therefore it is expected that an increase in barley's price at production region will decrease tendency of selling to state, so $\gamma_{6}$ will be negative.

Relative increase at guarantee price of wheat comparing with production's average cost (cost price) is another variable that has been used in function (1) which according to supply theory it has to have a positive relation with supply to state. Effectiveness of self consumption variation on selling tendency to state is measured by coefficient $\gamma_{9}$. 
Table 3. wheat selling to state sectional model estimating result

\begin{tabular}{|c|c|c|c|c|c|}
\hline parameter & coefficient & s. d. & parameter & coefficient & s.d. \\
\hline$\gamma_{0}$ & 0.001 & 0.216 & $\gamma_{6}$ & $1.2 \mathrm{E}-4$ & $1.4 \mathrm{E}-4$ \\
\hline$\gamma_{1}$ & $2.05 \mathrm{E}-8$ & $3.95 \mathrm{E}-8$ & $\gamma_{7}$ & $4.66 \mathrm{E}-5$ & $1.1 \mathrm{E}-4$ \\
\hline$\gamma_{2}^{* *}-4$ & $1.51 \mathrm{E}-6$ & $\gamma_{8}^{* *}$ & 0.835 & 0.096 \\
\hline$\gamma_{3}^{* *}$ & $2.74 \mathrm{E}-6$ & 0.019 & $\gamma 9 *$ & $-4.9 \mathrm{E}-6$ & $2.32 \mathrm{E}-6$ \\
\hline$\gamma_{4}^{* *}$ & 0.055 & 0.0004 & $\bar{R}_{2}$ & 0.767 & - \\
\hline$\gamma_{5}$ & 0.001 & $5.1 \mathrm{E}-6$ & $F$ & 25.1 & - \\
\hline
\end{tabular}

Note: (*), and (**) indicate significance at 1 and 5\%, respectively.

Data

Totally estimating a model can be done with time series or cross section datasets which each have advantages and disadvantages. The disadvantages of estimating with time series data set are incompleteness of needed information and effects of environmental change like variation of technology and people's reaction.

In cross section dataset it is possible to find all needed information by survey but the estimating conclusions in the best mode reveals the situation of the study section and there is no guarantee on estimating conclusion credits for other time sections. So choosing one of the two approaches of gathering data depends on the hypothesis, quantity and quality of data's.

In this study because of the following reasons we preferred to use cross section data set:

The subject is the great tendency of selling wheat to the new state, which this much tendency in last year's (ratio of selling with production) haven't been experienced (Table 3). Therefore possibly the previous data in wheat producers selling reactions to state can't help so much to examine hypothesis and get a conclusion from the study.

Some needed information for the model doesn't exist formally. For example working hours of equipment, quantity of water used, producers earning price (not formal purchasing price), production's miscellaneous (sundry) costs and,...however some other information exist in time series dataset but looks it may not have the essential accuracy, for example the quantity of labor used at wheat production in Golestan province has an unexpected variation range (in some years for example 1986 , the labor value of one hectare of wheat reported zero, but it is unbelievable). These disadvantages won't let coefficients estimating be done correctly and the model won't be adapted.

Time series of needed data from the view point of quantity are restricted. About wheat production, the oldest formal document is related to 1984 , which means if we have the documents till 2010 the number of data related to each variable will account 27 . Since we should have different hypothesis examines and variables that should be in the model, model's degree of freedom will decrease.

Because of above reasons, in this study section information related to production and selling in year 2010 have been collected in 11 townships of Golestan province by survey and have been used. Totally 252 questionnaires have been filled. Farmers selected from random sampling method.

\section{Discussion and conclusion}

\section{Estimation}

Also like acreage function, in supply model after prior estimating White test shows existence of inequality of variance between residential sections. With the same method compatibility (suitability) from coefficient's deviation of standard was done which its result is shown in Table 3.

In farmers' selling tendency to state function, which is the most important function, it is proved that production quantity has a positive and insignificant relationship. Therefore insignificance of production's quantity on selling tendency to state is shown. If we take wheat produced quantity of each producer as his scale of activity, the mentioned conclusion will show in time period of 2010 crop years is that small and big producers' tendency to sell to state didn't have significant difference.

On the contrary of production's quantity, production's increase to acreage increase from 2009 to 2010 has a positive and significant effect on selling approach. This means increase in farmer's yield in the period of time has positive effect-although little- on wheat selling to state. Another coefficient which has been significant is farm's distance to selling centers and has a positive effectpaying transportation cost in addition to purchase price has made a bigger tendency to sell to state for further wheat producers. Acreage covering by purchasing centers which is as a number of purchasing centers' effect index, however is negative and shows the positive effect of number of purchasing centers on selling more to state but it's insignificant.

One of the enormously significant variables is farmers' previous period's method of selling. Decision making in market (selling approach) like decision making in production (land allocation) can be completely traditional or completely economical (market orientation). Observing each farmer's condition in this range, estimate's decision making's coefficient of next period by previous period's decision making. A completely traditional farmer doesn't change his selling approach at
Popular article

CIndian Society for Education and Environment (iSee)
"Willingness to sell wheat for public distribution in Iran" http://www.indjst.org
Mojtaba Mojaverian Indian J.Sci.Technol. 
market in a period of time. Therefore in this situation $\gamma 8$ coefficient significantly will be equal to one. But for market orientation farmers- by paying attention to market's condition variation in period of time- mentioned coefficient will be equal to zero. In estimating above variable's coefficient for Golestan province, its' amount was 0.835 and completely significant (the most significant coefficient between model's coefficient). However, it has significant difference with one $\left({ }^{1} \mathrm{t}=(1-0.835) /(0.096)=1.7\right)$. Therefore, Golestan's province wheat producers, not only in cultivation model but also in selling approach, aren't completely traditional.

\section{Testing the Hypotheses}

In this part, by paying attention to model's estimated coefficients and their deviation standards, different hypotheses will be tested.

Increase in wheat's support price had motivated the farmers to sell to state: Above hypothesis can be explained in two ways, money term and real price. In money term, the producers react by observing announced guarantee price and without purchasing power. The second explanation is that real guarantee price or relative guarantee price is the base of estimation in Table 3 . In this part increase in each farmer's recovers guarantee price to production average cost's increase (final price) have been chosen as the basis. Relative variation price has a positive and completely significant effect on selling tendency. Paying attention to the latter variable shows that wheat producers don't have money illusion (they don't only pay attention to money term) and observe price variation by paying attention to cost variation.

Improvement in Farm management will increase wheat selling to state: Management improvement by choosing correct amount of inputs and appraise well crop managing will cause an increase in input's effect on yield.

The calculated variable for management was entered in function (1) to test the hypothesis to illustrate crop management improvement's impression on market's management (selling approach). Management level variable didn't have significant effect on wheat's selling approach. Apparently crop management level didn't have monotonous and significant effect on market management.

Relative decrease in cattle's food price will motivate wheat selling to state: By paying attention to cattle's food ration variety, the kind of cattle, fattening location and different cattle's food price, barely was chosen as a scale of cattle's food and its' price was chosen for testing above hypothesis. Estimated coefficient for barley's price have been districted positive (unexpected) and insignificant. Therefore above hypothesis will be rejected.

However, test's conclusion should be stated with precaution. Because(i) barely is not the only cattle food and there are substitutions for it and(ii) animal husbandry importance isn't equal in all regions of Golestan province, maybe if important animal husbandry regions were separated from other regions (for example by using dummy variable), barley's price importance and its variation on wheat's selling motivation to state was evaluated better.

Increasing in number of purchasing centers will motivate wheat producers to sell to state: To test above hypothesis, the purchasing center's acreage coverage which farmer's field is allocated there, have been entered as a variable. In an honest mode of above hypothesis, maintained variable's coefficient should be negative and significant. With an increase in number of purchasing centers in environs of farmer's field, acreage coverage will decrease and therefore the mentioned variable will decrease.

Estimation's conclusion shows, however, averagely there is negative relationship (as hypothesis's expectation) but from statistical point of view it doesn't make a suitable significant level. From this point of view by developing purchasing centers-at least in short term-we can't increase Golestan's wheat producers selling tendency.

Self-consumption's decrease has increased selling tendency to state: In this study, self-consumption of wheat means, the product's quantity which wasn't sent to market by wheat producers. By this order, selfconsumption in addition to farmers family annual food, consists of its' cattle's food and also next year's seed. Conclusion's supply function estimation in Table 1 shows the mentioned coefficient is negative and significant (in 5\% level of significance).Therefore by decreasing selfconsumption because of distributing subsided flour at production, preparing and distributing cattle's food will indirectly increase selling tendency to state.

\section{Conclusion and suggestions}

This study focused on reasons of increase in wheat producers' surplus wheat selling to state in $2010 \mathrm{crop}$ year. For answering the study's questions and testing the hypotheses, we used a function of selling tendency to state. Needed information was collected by questionnaire from 252 wheat producers. Conclusions illustrate that Yield increase will cause production increase, however it will increase the amount of selling to state but it didn't have a significant effect on selling tendency to state from province's producers.

Support price increases effect on wheat selling tendency to state in the model wasn't significant, but increases effect in relative guarantee price (to cost changes) is positive and completely significant.

Self-consumption's decrease will increase selling tendency to state. Purchasing centers developing -at least in short term- didn't have a significant effect on selling tendency. Wheat producer's traditionalism investigation on selling to state shows that complete traditionalism doesn't exist.

\section{Acknowledgement}

This study was done with management studies and agricultural institute's support and Golestan's agricultural office's cooperation. We are grateful to tank Dr.Gilak, Dr.Mahmoudi, Kavyani, Jalali, and Ghaemifor their helps. 


\section{References}

1. Baldwin RE (1970) Non-tariff distortions of International trade, Washington, DC: Brookings.

2. Baldwin RE (1984) Trade policies in developed countries in Jones, R. Kenen P. (Eds.). Handbook Intl. Econom., North-Holland, Amsterdam. pp: 517-619.

3. Baldwin RE and Richardson JD (1984) Recent U.S. Trade policy and its global implications. Working Paper No. 1330. National Bureau of Econom. Res.

4. Evenett SJ and Hoekman BM (2005) Government procurement: market access, transparency, and multilateral trade rules. Euro. J. Pol. Econom. 21, 163-183.

5. Garcia RJ and Randall A (1994) A Cost function analysis to estimate the effects of fertilizer policy on the supply of wheat and corn. Rev. Agr. Econom.16, 215-230.

6. Kherallah M, Minot N and Gruhn P (2003) Adjustment of wheat production to market reform in Egypt. Res. Middle East. Econom. 5, 133-159.

7. Miyagiwa K (1991) Oligopoly and discriminatory government procurement Policy. Amer. Econom. Rev. 81, 1320-1328.

8. Morzuch BJ, Weaver RD and Helmberger PG (1980) Wheat acreage supply response under changing farm programs. Amer. J. Agr. Econom. 62, 29-37.

9. Sidhu SS and Baanante CA (1981) Estimating farmlevel Input demand and wheat supply in the Indian Punjab using a Translog profit function. Amer. J. Agr. Econom. 63, 237-246.

10. Taylor TK (2003) Modeling offset policy in government procurement. J. Pol. Mod. 25, 985-998.

11. Unknown, Statistics and information technology office, Agricultural statistic book (first volume) Cultivation and horticultural productions (different cultivation years), Programming and economical assistant of agricultural ministry.

12. Unknown, Statistics office and computerizing service of agricultural planning management, Rural Cooperative Organization. 